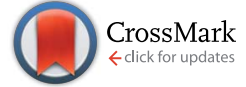

Cite this: RSC Adv., 2017, 7, 4226

\title{
Preparation of 4-vinylpyridine (4VP) resin and its adsorption performance for heavy metal ions
}

\author{
Youning Chen, Wei Zhao and Juncai Zhang \\ The study focused on the preparation of a chelating resin with pyridine ring as the functional group. The 4VP \\ monomer was directly grafted on the surface of CMPS resin via SI-ATRP, and the performance of adsorption \\ of resin for $\mathrm{Cr}(\mathrm{VI}), \mathrm{Pb}(\|), \mathrm{Cr}\left({ }^{\prime \prime}\right), \mathrm{Zn}(॥)$, and $\mathrm{Cd}(॥)$ was determined. With the extension of ATRP time and increase \\ of 4VP consumption, the 4VP grafting rate was linearly increased, indicating an increase in the density of the \\ pyridine ring on the resin surface. Adsorption experiments indicated that the adsorption capacity of the resin \\ for the metal ions considerably improved when compared with that of those reported in literature, whereas \\ the desorption rate and reusability were equivalent to those of the conventional resins. When the $\mathrm{pH}$ value \\ was greater than 5.0, $\mathrm{Pb}(॥), \mathrm{Cr}\left({ }^{\prime \prime}\right), \mathrm{Zn}(॥)$, and $\mathrm{Cd}(॥)$ ions could be adsorbed; however, when the $\mathrm{pH}$ value was \\ less than 3.0, $\mathrm{Cr}(\mathrm{VI})$ could be selectively adsorbed. These results are indicative of a potential application of \\ the resin in the treatment of heavy metal wastewater. Therefore, adoption of one-step SI-ATRP is one of the \\ effective methods for preparing a chelating resin with high capacity via the selection of an appropriate \\ functional monomer.
}

Received 15th November 2016 Accepted 19th December 2016

DOI: 10.1039/c6ra26813g

www.rsc.org/advances

\section{Introduction}

A traditional way to prepare a chelating resin is generally to functionalize the surface of the material with ligands of low molecular weight using covalent bonds. Due to the limited number of reaction sites on the material surface, the introduced functional group has low density, leading to a low adsorption volume. ${ }^{1,2}$ As is reported in some studies, the use of functional polymers to modify the material surface can significantly improve the density of the functional groups on the material surface; therefore, during recent years, some excellent modification methods, such as surface coating method and "Grafting to" and "Grafting from" chemical grafting methods, have emerged. ${ }^{3,4}$ Different from the "Grafting to" method, namely the direct anchorage of functional polymers onto the material surface, "Grafting from" method first use the molecular selfassembly technology to construct a high-oriented and closelybonded "initiator self-assembly molecular layer" on the resin surface, and then utilize a living polymerization technique to in situ polymerize the small molecular monomers on the material surface. It is characterized with the abilities to form highdensity polymer molecular brushes on the material surface and achieve the goal of connecting as many as possible functional groups within a limited area., ${ }^{5,6}$ Surface-initiated atom transfer radical polymerization (SI-ATRP) is a "Grafting from" method developed during recent years and has been preliminarily applied to the preparation of adsorbing materials such as

College of Chemistry and Chemical Engineering, Xianyang Normal College, Xianyang 712000, China.E-mail: cyn5363@163.com chromatographic fixed phase, ${ }^{7,8}$ chelating and ion exchange resins, ${ }^{9}$ and chelating and ion exchange adsorption films. ${ }^{10}$ Our group has proven that SI-ATRP is one the new methods for the preparation of high volume adsorbing materials for anion and cation-exchange membranes. ${ }^{11,12}$

From the perspective of monomer structures, vinyl pyridine contains $-\mathrm{N}=$, which has one unused electron pair that is not involved in the conjugated system on the ring; therefore, the vinyl pyridine modified resin has advantages and specific functions as compared to those of the styrene resin. ${ }^{13-15}$ The carbon atoms and nitrogen atoms on the pyridine ring are bonded via $\mathrm{sp}^{2}$ hybrid orbitals. Each atom in the ring contains $1 \mathrm{p}$ orbital, and each $\mathrm{p}$ orbital contributes 1 electron for a total of $6 \mathrm{p}$ electrons; thus, an annular enclosed conjugated system is formed that conforms to the Huckel's rule $(4 n+2)$ of aromaticity. One $\mathrm{sp}^{2}$ hybrid orbital can also be found on the nitrogen atom, occupied by one lone pair of electrons, which is not involved in bonding and can therefore bind with the protons; therefore, pyridine is alkaline and also acts as a good ligand, which can bind or react with multiple metal ions to form complexes. 4-Vinylpyridine block copolymer is a very important type of polymer that can manifest an excellent performance due to the presence of nitrogen atoms on the pyridine ring; therefore, they can form self-assembly supramolecular structures ${ }^{16}$ and are capable of coordinating with metal ions. ${ }^{17,18}$ As reported in some previous studies, the 4-vinylpyridine-grafted polyethylene terephthalate fiber can effectively remove $\mathrm{Cr}(\mathrm{VI}), \mathrm{Cu}(\mathrm{II})$, and $\mathrm{Cd}(\mathrm{II})$ from a solution, ${ }^{19}$ and the 4-vinylpyridine-modified polyethyleneglycol dimethacrylate and glycol dimethacrylate microspheres exhibit a good adsorption performance for $\mathrm{Pb}(\mathrm{II}), \mathrm{Cd}(\mathrm{II}), \mathrm{Cr}(\mathrm{III})$, and $\mathrm{Cu}(\mathrm{II}) .^{20}$ 
Benzyl chloride is an effective initiator in the ATRP reactions and chloromethylated polystyrene contains benzyl chloride initiation sites. In this study, based on 4-vinylpyridine (4VP) as the functional monomer, a novel type of poly-4-vinylpyridine chelating polymeric adsorbent (P4VP- $g$-PS) was prepared using the SI-ATRP method to directly modify $4 \mathrm{VP}$ on the CMPS resin surface. The synthetic resin obtained using the abovementioned resin to adsorb $\mathrm{Cr}(\mathrm{VI}), \mathrm{Pb}$ (II), $\mathrm{Cr}$ (III), $\mathrm{Zn}$ (II), and $\mathrm{Cd}(\mathrm{II})$ has been characterized with a relatively high adsorption volume and can be repeatedly used, providing a feasible idea and method for the preparation of novel polymeric adsorbent.

\section{Experiment}

\subsection{Reagents and devices}

Chloromethylated polystyrene (Xi'an Lanxiao Science and Technology New Material Co., Ltd., with a chlorinity of $18 \%$ (mass fraction), a content of cross-linking agents of 6\% (mass fraction)), 4-vinylpyridine (CP, Shanghai Aladdin), cuprous bromide (CP, Tianjin Chemical Reagent Factory), 2,2'-bipyridine (CP, Tianjin Chemical Reagent Factory), tetrahydrofuran (CP, Tianjin Hedong District Hongyan Reagent), acetone (CP, Luoyang Chemical Reagent Factory), methanol (CP, Tianjin Hedong District Hongyan Reagent), ethanol (CP, Luoyang Chemical Reagent Factory), sodium acetate (CP, Tianjin Hedong District Hongyan Reagent), glacial acetic acid (CP, Tianjin Hedong District Hongyan Reagent), sodium ethylene diamine tetraacetate (CP, Tianjin Hengxing Chemical Reagent Factory), $\mathrm{K}_{2} \mathrm{Cr}_{2} \mathrm{O}_{7}$ (AR, Tianjin Fuchen Chemical Reagent Factory), $\mathrm{ZnSO}_{4} \cdot 7 \mathrm{H}_{2} \mathrm{O}$ (AR, Tianjin Fuchen Chemical Reagent Factory), $\mathrm{Pb}\left(\mathrm{NO}_{3}\right)_{2}$ (AR, Tianjin Fuchen Chemical Reagent Factory), $\mathrm{Cr}\left(\mathrm{NO}_{3}\right)_{3} \cdot 9 \mathrm{H}_{2} \mathrm{O}$ (AR, Tianjin Fuchen Chemical Reagent Factory), and $\mathrm{Cd}\left(\mathrm{NO}_{3}\right)_{2} \cdot 4 \mathrm{H}_{2} \mathrm{O}$ (AR, Tianjin Fuchen Chemical Reagent Factory).

TENSOR type 27 Fourier transform infrared spectrometer (Bruker, Germany), Rario type II elemental analyser (Elementar, Germany), novAA400 atomic absorption spectrometer (Analytik Jena AG, Germany), KYKY-2800B scanning electron microscope (KYKY Technology Co., Ltd., Beijing), and K-Alpha X-ray electron spectrometer (Termo Fisher, USA); Micromeritics ASAP 2010 (Georgia USA).

\subsection{Preparation of P4VP- $g$-PS resin}

(1) $5 \mathrm{~g}$ of chloromethylated polystyrene (macromolecular initiator), $0.5 \mathrm{~g}$ of 2,2'-bipyridine, $0.05 \mathrm{~g}$ of cuprous bromide, $50 \mathrm{~mL}$ of acetone, and a certain amount of monomer 4-vinylpyridine were combined; after freezing and evacuation, nitrogen gas was purged for 3 cycles for about $30 \mathrm{~min}$; and the abovementioned substances were allowed to react at $40{ }^{\circ} \mathrm{C}$ for a certain period of time.

(2) Removal of copper ion: the products were washed using acetone followed by stirring in 10\% EDTA (EDTA/ethanol volume ratio: $1: 1$ ) for 24 hours. Then, they were filtered and washed with water and finally with ethanol. They were dried under vacuum at $35^{\circ} \mathrm{C}$.
The polymerization time and monomer dosage were used to control the degree of grafting (GD) of 4-vinylpyridine in CMPS and GD can be calculated using the following equation:

$$
\operatorname{GD}(\%)=\left(W_{\mathrm{a}}-W_{\mathrm{b}}\right) / W_{\mathrm{b}} \times 100 \%
$$

where $W_{\mathrm{a}}-$ mass of the resin after reaction $(\mathrm{g})$ and $W_{\mathrm{b}}$-mass of the resin before reaction $(\mathrm{g})$.

\subsection{Structural characterization of resin}

Infrared spectroscopy, X-ray photoelectron spectroscopy (XPS), scanning electron microscopy (SEM), and elemental analysis were used to characterize the CMPS and P4VP-g-PS resins.

\subsection{Monocomponent adsorption experiment}

The tests using P4VP-g-PS to adsorb $\mathrm{Cr}(\mathrm{VI}), \mathrm{Pb}$ (II), $\mathrm{Cr}$ (III), $\mathrm{Zn}$ (II), and $\mathrm{Cd}(\mathrm{II})$ at a specified temperature proceeded according to the following steps:

Adsorption isotherm test: the $\mathrm{pH}$ value of the $\mathrm{Cr}(\mathrm{vI})$ stock solution was adjusted to 3.0 , whereas the $\mathrm{pH}$ value of the $\mathrm{Pb}$ (II), $\mathrm{Cr}$ (III), Zn(II), and $\mathrm{Cd}(\mathrm{II})$ stock solutions was adjusted to 5.0. The solutions were then diluted using NaAc-HAc buffer solution to obtain the solutions at different concentrations (from $0.5 \mathrm{mmol} \mathrm{L}^{-1}$ to $8.0 \mathrm{mmol} \mathrm{L}^{-1}$ ). $0.1 \mathrm{~g}$ of resin was added to $100 \mathrm{~mL}$ of the abovementioned solutions. The beaker was placed onto a constant temperature oscillator and oscillated at a rate of $200 \mathrm{rpm}$ at a constant temperature for 12 hours. Curves were plotted for $Q_{\mathrm{e}}$ versus $C_{\mathrm{e}}$ to determine the $\mathrm{Cr}(\mathrm{VI}), \mathrm{Pb}(\mathrm{II}), \mathrm{Cr}(\mathrm{III}), \mathrm{Zn}(\mathrm{II})$, and $\mathrm{Cd}(\mathrm{II})$ adsorption isotherms.

Adsorption kinetic test: the initial concentration of $\mathrm{Cr}(\mathrm{vI})$, $\mathrm{Pb}$ (II), Cr(III), Zn(II), and Cd(II) solutions was $5 \mathrm{mmol} \mathrm{L}^{-1}$, the $\mathrm{pH}$ value of the $\mathrm{Cr}(\mathrm{VI})$ solution was 3.0, and the $\mathrm{pH}$ value of $\mathrm{Pb}(\mathrm{II})$, $\mathrm{Cr}$ (III), $\mathrm{Zn}$ (II), and $\mathrm{Cd}$ (II) solutions was 5.0; the $\mathrm{pH}$ value was not adjusted during the adsorption process. $1 \mathrm{~mL}$ of solution was extracted at regular intervals; atomic absorption spectrometry (AAS) was used to determine the concentration of metal ions in the solution and the adsorption volume of the resin was calculated. A dynamical parameter curve was plotted for adsorptive capacity $(Q)$ versus adsorption time $(T)$.

During the study of the effects of $\mathrm{pH}$ on the adsorptive capacity, the HAc-NaAc buffer solution was used to prepare the $\mathrm{Cr}(\mathrm{VI}), \mathrm{Pb}(\mathrm{II}), \mathrm{Cr}(\mathrm{III}), \mathrm{Zn}$ (II), and $\mathrm{Cd}(\mathrm{II})$ stock solutions at different $\mathrm{pH}$ values at an initial concentration of $5 \mathrm{mmol} \mathrm{L}^{-1}$.

After the adsorption was completed, $0.2 \mu \mathrm{m}$ membrane filtration was performed to separate the resin and atomic absorption spectroscopy (AAS) was used to determine the concentration of the residual metal ions in the filtrate. Finally, the adsorptive capacity $(Q)$ was calculated as follows:

$$
\text { Adsorptive capacity, } Q=\frac{\left(C_{0}-C\right) V}{W}
$$

$Q$-adsorptive capacity $\left(\mathrm{mmol} \mathrm{g}^{-1}\right) ; C_{0}$ and $C$ represent the initial concentration of the metal ions in the solution and the concentration of those after adsorption $\left(\mathrm{mmol} \mathrm{L}^{-1}\right)$, respectively; $V$ - volume (L); and $W$ - the resin mass $(\mathrm{g})$. 


\subsection{Selective adsorption}

$0.1 \mathrm{~g}$ of resin was added to a binary system consisting of $\mathrm{Cr}(\mathrm{vI})-$ $\mathrm{Pb}(\mathrm{II}), \mathrm{Cr}(\mathrm{VI})-\mathrm{Cr}(\mathrm{III}), \mathrm{Cr}(\mathrm{VI})-\mathrm{Zn}$ (II), or $\mathrm{Cr}(\mathrm{VI})-\mathrm{Cd}(\mathrm{II})$, as well as a quinary system consisting of $\mathrm{Cr}(\mathrm{VI})-\mathrm{Pb}$ (II) $-\mathrm{Cr}$ (III)-Zn(II)-Cd(II) for adsorption; the initial concentration of all the metal ions was $5 \mathrm{mmol} \mathrm{L}^{-1}$ and the $\mathrm{pH}$ value was 3.0 ; the $\mathrm{pH}$ value was not adjusted during the adsorption process. Determination of the adsorptive capacity was carried out according to the abovementioned method.

\subsection{Desorption and repeated use of metal ions}

The performance for repeated use is a very important index or parameter to determine whether the adsorption materials are of value for practical applications. The polymeric adsorbents saturated with $\mathrm{Cr}(\mathrm{vI})$ are added to a $1 \mathrm{~mol} \mathrm{~L}^{-1} \mathrm{KOH}$ solution, whereas the resin saturated with $\mathrm{Pb}(\mathrm{II}), \mathrm{Cr}(\mathrm{III}), \mathrm{Zn}$ (II), and $\mathrm{Cd}(\mathrm{II})$ was added to a $0.1 \mathrm{~mol} \mathrm{~L}^{-1} \mathrm{HNO}_{3}$ solution and stirred at room temperature for 5 hours to desorb the metal ions that were adsorbed on the material surface. The degree of desorption was calculated according to following formula (3):

Degree of desorption $(\%)=$ mass of the desorbed metal ions/mass of the adsorbed metal ions $\times 100 \%$

To further determine the reusability of the resin, 10 consecutive adsorption-desorption cycles were conducted.

\section{Results and discussion}

\subsection{Preparation of 4-vinylpyridine (4VP) resin}

The synthetic process for the preparation of 4-vinylpyridine (4VP) resin is shown in Fig. 1. SI-ATRP was used to directly graft the 4-vinylpyridine monomer on the surface of CMPS resin. During the ATRP polymerization reaction, the initiator was generally an alkyl halide containing conjugation-inducing groups at the $\alpha$ site, whereas the catalyst was a low valent transition metal chloride or bromide. Since the metal halide has a poor solubility, coordination agents must be used to increase the dissolution of the catalysts. In this study, $\mathrm{CuBr}$ was the catalyst, 2,2'-bipyridine was the coordination agent, chloromethylated and polystyrene were directly used as solid initiator(s) due to the content of the chloromethylated substance itself. The introduction of poly 4-vinylpyridine molecular brushes on the surface of the resin via the SI-ATRP method could increase the density of the pyridine rings on the surface of the material. During SI-ATRP, the amount of polymers grafted on the surface is associated with the polymerization time and monomer concentration. Fig. 2 and 3 present the relationship of grafting degree with the polymerization time and monomer concentration.

As is shown in Fig. 2, within 10 hours, the grafting degree of 4-vinylpyridine linearly increased with the increase in the polymerization time, indicating that the thickness of P4VP on the resin surface linearly increased. After 10 hours, the degree of grafting reached $75 \%$. However, with the prolonged polymerization time, the growth rate gradually became slow due to the following reasons: with the progress of the reaction, the concentration of the monomer 4VP significantly decreased, the high rate of $4 \mathrm{VP}$ at the beginning was somewhat controlled, and double-base coupling and double-base disproportionation termination were the dominant reactions. As is shown in Fig. 3, the degree of grafting linearly increased with the increase in the monomer dosage. The abovementioned analysis indicates that the polymerization of 4-vinylpyridine on the material surface belongs to the active controllable polymerization, showing that on controlling the polymerization time and monomer dosage, the grafting amount of 4-vinylpyridine can be controlled.

The relationship between the grafting degree and adsorptive capacity was investigated. Fig. 2 and 3 present the volume of $\mathrm{Cr}$ (VI), $\mathrm{Pb}$ (II), $\mathrm{Cr}$ (III), $\mathrm{Zn}$ (II), and $\mathrm{Cd}$ (II) adsorbed by the P4VP resin at different ATRP time intervals and at different 4VP dosages. As is shown in Fig. 2, within 10 hours, with the prolonging of the ATRP reaction time, the adsorptive capacity linearly increased, presenting a direct proportion with the grafting amount of 4vinylpyridine on the resin surface. After 10 hours, the rising

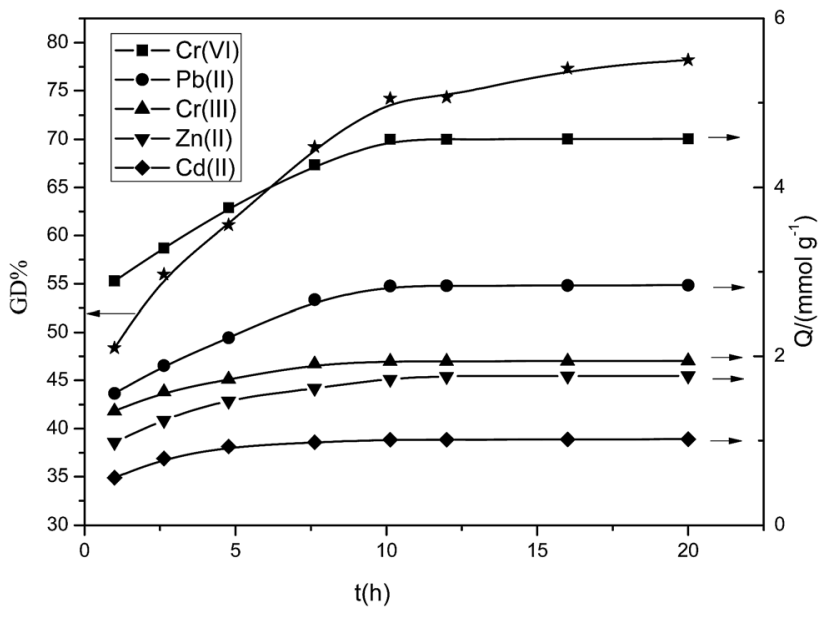

Fig. 2 Effects of ATRP time on the adsorption capacity and degree of grafting.

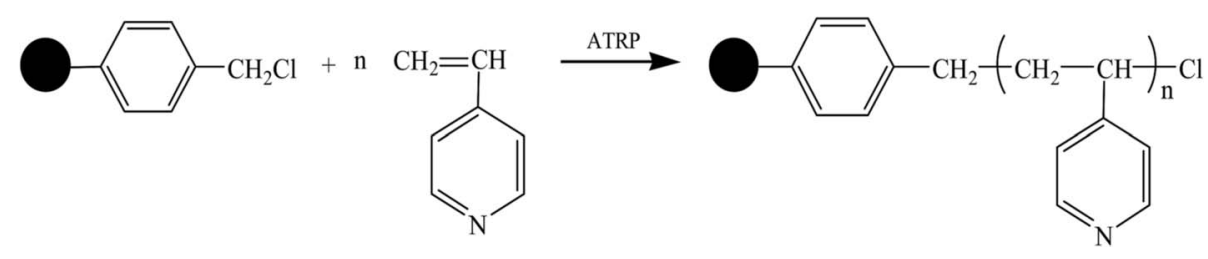

Fig. 1 The synthetic route for the preparation of P4VP-g-PS resin. 


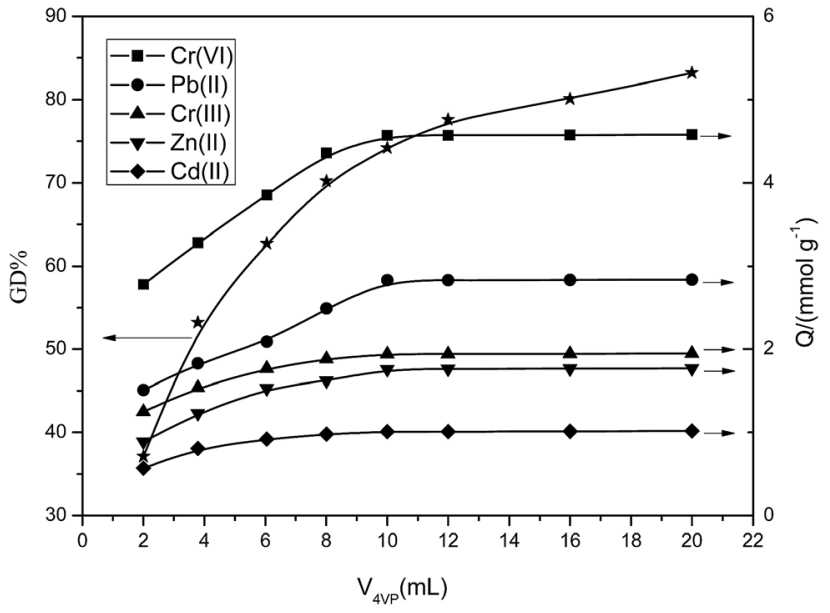

Fig. 3 Effects of the amount of 4VP on the grafting density and adsorption capacity.

tendency of the adsorptive capacity becomes slow probably due to the following reasons: with the prolonging in the polymerization time, the surface and interiors of the resin were covered with relatively long P4VP polymer brushes; however, the volume of the resin surface holes was limited, such that when the polymers obstruct the holes, the ATRP reaction will stop. As is shown in Fig. 3, when the 4VP dosage is within $10 \mathrm{~mL}$, the adsorptive capacity linearly increases with the monomer dosage and is in a direct proportion with the amount of $4 \mathrm{VP}$ grafted on the resin surface. When the volume exceeds $10 \mathrm{~mL}$, the rising tendency of the adsorptive capacity becomes slow probably due to the following reasons: with the increase in the monomer dosage, the density of $4 \mathrm{VP}$ on the resin surface increases, resulting in varying degrees of obstruction in the holes on the resin surface and preventing the reactions from proceeding further. Thus, the abovementioned analyses indicate that it is appropriate to control the ATRP reaction time and 4VP dosage within $10 \mathrm{~h}$ and $10 \mathrm{~mL}$, respectively.

\subsection{Resin characterization}

Infrared spectroscopy, scanning electron microscopy, elemental analysis, and XPS were used to characterize the CMPS and P4VP$g$-PS resin.

The infrared spectra are shown in Fig. 4. In Fig. 4(a), the absorption peaks at 759 and $698 \mathrm{~cm}^{-1}$ represent the stretching vibrations of $\mathrm{C}-\mathrm{Cl}$ in $-\mathrm{CH}_{2} \mathrm{Cl}$. After surface modification, when compared with Fig. 4(a), obvious changes in these two characteristic absorption peaks were observed (Fig. 4(b)). In Fig. 4(b), the $\mathrm{C}=\mathrm{N}$ absorption peaks on the pyridine ring appeared near $1605 \mathrm{~cm}^{-1}, 1597 \mathrm{~cm}^{-1}, 1557 \mathrm{~cm}^{-1}$, and $1415 \mathrm{~cm}^{-1}$ are the stretching vibration peaks of the pyridine ring, indicating that pyridine groups have been successfully grafted on the surface of the chloromethylated polystyrene resin.

Analysis of the XPS spectra (Fig. 5), showed the modification in the resin structure. There was no $\mathrm{N}$ absorption peak in the unmodified CMPS resin; after the SI-ATRP reaction, an N1s absorption peak appeared at $399.8 \mathrm{eV}$ in the spectrum of the

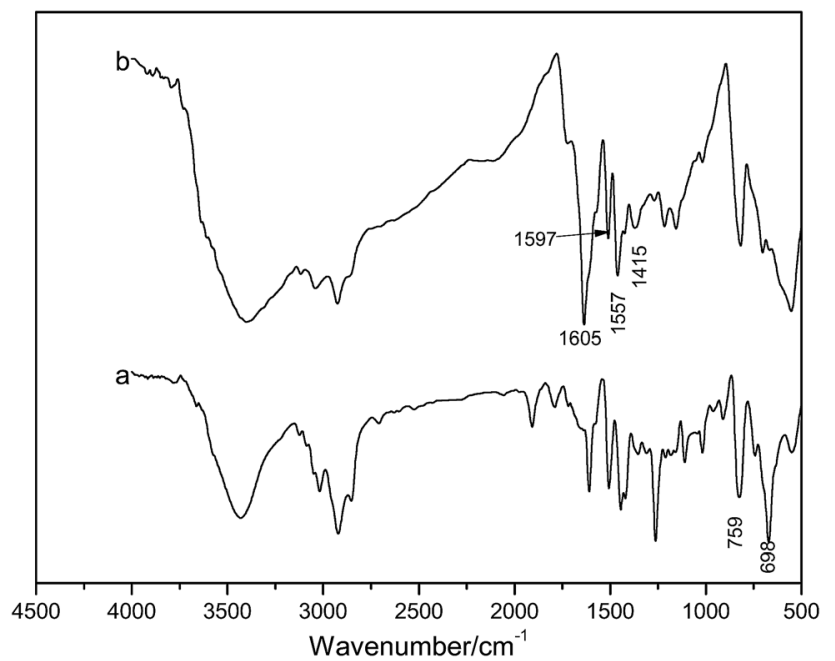

Fig. 4 FTIR spectrum of (a) CMPS and (b) P4VP-g-PS.

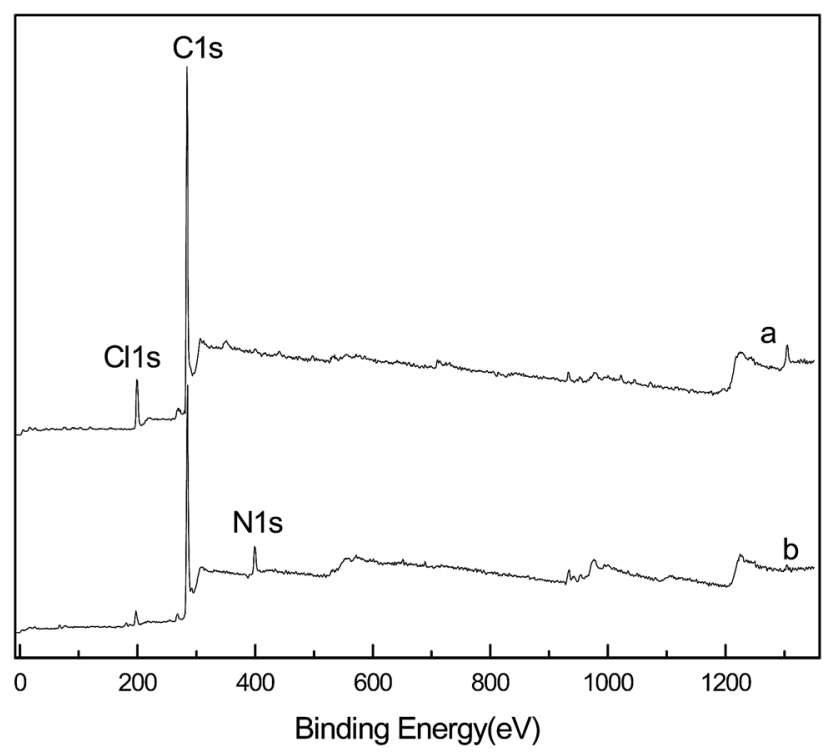

Fig. 5 XPS wide scan of (a) CMPS and (b) P4VP-g-PS.

P4VP-g-PS resin, indicating that pyridine rings were successfully grafted on the resin surface. XPS analysis also indicated the content of the elements on the resin surface, as shown in Table 1.

As shown in Table 1, the $\mathrm{N}$ content on the surface of P4VP- $g$ PS resin increases with the increase in the polymerization time. This further verified that the degree of grafting would increase with the increase in the polymerization time.

Peak splitting was further performed for the C1s peak to obtain the detailed information about the changes in the components of the resin surface (Fig. 6).

For CMPS, the C1s peak was split into two peaks at 284.3 and $286.2 \mathrm{eV}$ (Fig. 6(A)), which correspond to C-C and C-C1, respectively. For P4VP-g-PS, the C1s peak was split into three peaks at $284.13 \mathrm{eV}, 285.6 \mathrm{eV}$, and $286.92 \mathrm{eV}$ (Fig. 6(B)), which correspond to $\mathrm{C}-\mathrm{C}, \mathrm{C}-\mathrm{N}$, and $\mathrm{C}-\mathrm{Cl}$ bonds, respectively, again 
Table 1 Elemental compositions of resins

\begin{tabular}{llll}
\hline & \multicolumn{2}{l}{ Elemental content/\% } \\
\cline { 2 - 4 } Sample & $\mathrm{C}$ & $\mathrm{Cl}$ & $\mathrm{N}$ \\
\hline CMPS & 81.4 & 8.12 & 0 \\
PS-P4VP(ATRP1h) & 88.55 & 3.16 & 4.57 \\
PS-P4VP(ATRP3h) & 67.92 & 6.15 & 5.06 \\
PS-P4VP(ATRP5h) & 72.09 & 5.41 & 5.23 \\
PS-P4VP(ATRP8h) & 75.02 & 2.03 & 5.36 \\
PS-P4VP(ATRP10h) & 74.02 & 3.05 & 5.48 \\
PS-P4VP(ATRP16h) & 77.84 & 4.83 & 5.51 \\
PS-P4VP(ATRP20h) & 85.81 & 3.19 & 6.46 \\
& & &
\end{tabular}

indicating that the pyridine ring was successfully grafted on the resin surface.

The differences in surface topography of the resin before and after the modification were studied by scanning electron microscopy. Fig. 7 displays the SEM images of the CMPS resin and P4VP-g-PS resin, indicating that obvious changes have occurred in the surface topography of the modified resin. A comparison with the non-modified CMPS resin indicates that the surface of P4VP- $g$-PS resin became smooth. The probable reasons are as follows: after the use of ATPR technology to graft the 4VP monomer on the CMPS resin surface, the surface is covered with high-density polymer molecular brushes, partially obstructing the original resin holes and therefore making the modified resin surface smooth.

\subsection{Adsorption test}

3.3.1 Adsorption isotherm. Adsorption isotherms are often used to measure the adsorption performance of the chelating resins for heavy metal ions. The adsorption isotherms of the P4VP-g-PS resin against $\mathrm{Cr}(\mathrm{VI}), \mathrm{Pb}(\mathrm{II}), \mathrm{Cr}(\mathrm{III}), \mathrm{Zn}(\mathrm{II})$, and $\mathrm{Cd}(\mathrm{II})$ at $25{ }^{\circ} \mathrm{C}$ are shown in Fig. 8.

Langmuir and Freundlich adsorption isotherm models were used to explain the experimental data for adsorption. According to the Langmuir model, adsorption of metal ions happened on monomolecular layers with even surfaces, whereas according to the Freundlich model, adsorption of metal ions happened on heterogeneous surfaces. Langmuir adsorption isotherm models are shown in formula (4):

$$
\frac{C_{\mathrm{e}}}{Q_{\mathrm{e}}}=\frac{C_{\mathrm{e}}}{Q_{0}}+\frac{1}{Q_{0} b}
$$

where $Q_{\mathrm{e}}$ represents the adsorptive capacity $\left(\mathrm{mmol} \mathrm{\textrm {g } ^ { - 1 }}\right), C_{\mathrm{e}}$ represents the equilibrium concentration of the metal ions $\left(\mathrm{mmol} \mathrm{L}{ }^{-1}\right), Q_{0}$ represents the saturation adsorption $(\mathrm{mmol}$
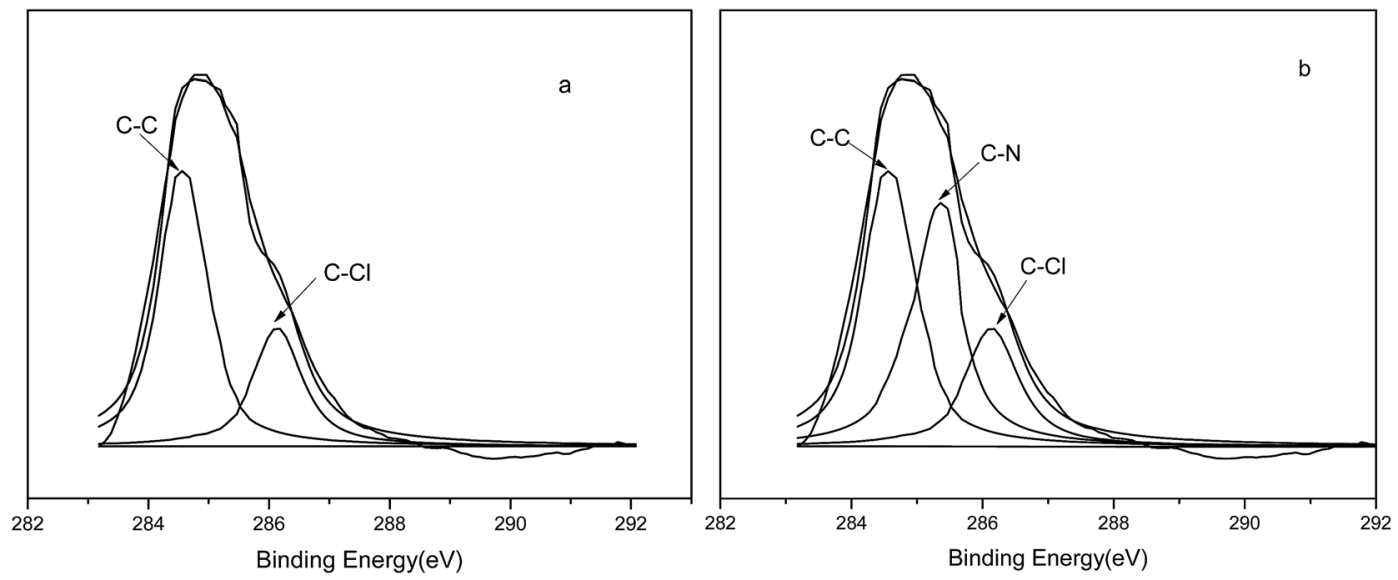

Fig. 6 C1s core-level spectra of (a) CMPS and (b) P4VP-g-PS.

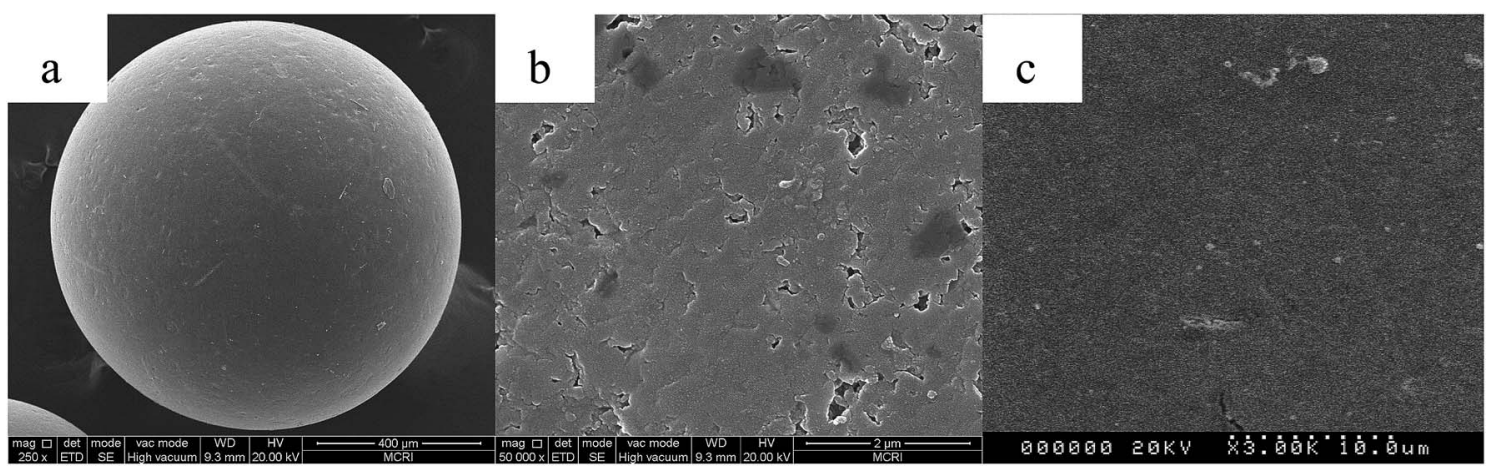

Fig. 7 SEM images of (a) and (b) CMPS, and (c) P4VP-g-PS. 


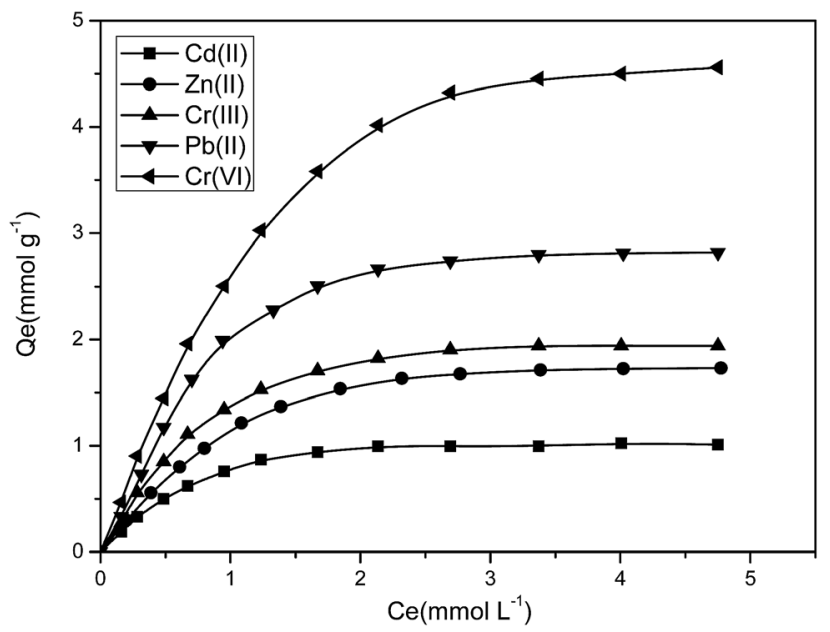

Fig. 8 Adsorption isotherms of P4VP-g-PS resin for $\mathrm{Cr}(\mathrm{VI}), \mathrm{Pb}(\mathrm{II}), \mathrm{Cr}(\mathrm{II})$, $\mathrm{Zn}(\|)$, and $\mathrm{Cd}(\|)$ at $25^{\circ} \mathrm{C}(\mathrm{Cr}(\mathrm{vI})$ at $\mathrm{pH} 3.0, \mathrm{~Pb}(\|), \mathrm{Cr}(\|)), \mathrm{Zn}(\|)$, and $\mathrm{Cd}(\|)$ at $\mathrm{pH}$ 5.0; contact time: $12 \mathrm{~h}$; adsorbent dose: $0.1 \mathrm{~g}$ ).

$\left.\mathrm{g}^{-1}\right)$, and $b$ is the Langmuir adsorption constant. The Langmuir constant has the following relationship with the adsorption equilibrium constant in the solid-liquid phase (aqueous solution):

$$
b=\left(K_{\mathrm{C}}-1\right) \times M / \rho
$$

where $M$ and $\rho$ represent the molar mass $\left(\mathrm{g} \mathrm{mol}^{-1}\right)$ and density ( $\mathrm{g} \mathrm{L}^{-1}$ ) of the solvent water, respectively.

A plot of $C_{\mathrm{e}} / Q_{\mathrm{e}}$ versus $C_{\mathrm{e}}$ can generate a straight line with slope of $1 / Q_{0}$ and intercept of $1 / Q_{0} b$. Analysis of the experimental data obtained from the Langmuir adsorption isotherm model revealed that $C_{\mathrm{e}} / Q_{\mathrm{e}}$ had a linear relationship with $C_{\mathrm{e}}$ and indicated that the adsorption behavior conforms to the Langmuir adsorption isotherm model. The values of $b, Q_{0}$, and linearly dependent coefficient are shown in Table 2.

The Freundlich adsorption isotherm model is shown in formula (6):

$$
\ln Q_{\mathrm{e}}=\ln K_{\mathrm{F}}+\frac{1}{n} \ln C_{\mathrm{e}}
$$

where $K_{\mathrm{F}}$ is the empirical parameter and $n$ is the Freundlich constant. A plot of $\ln Q_{\mathrm{e}}$ versus $\ln C_{\mathrm{e}}$ can generate a straight line with a slope of $1 / n$ and intercept of $\ln K_{\mathrm{F}}$. The values of $K_{\mathrm{F}}, n$, and the linearly dependent coefficient are shown in Table 2.
The value of the linearly dependent coefficient $R^{2}$ verified that the Langmuir model was a better fit for the experimental data than the Freundlich model; therefore, the adsorption process can be described using the Langmuir model, indicating that the adsorption of resin on heavy metal ions belong to the monomolecular layer adsorption.

As shown in Table 2, the maximum adsorptive capacity of P4VP-g-PS resin for $\mathrm{Cr}(\mathrm{VI}), \mathrm{Pb}(\mathrm{II}), \mathrm{Cr}(\mathrm{III}), \mathrm{Zn}$ (II), and $\mathrm{Cd}(\mathrm{II})$ was $4.56 \mathrm{mmol} \mathrm{g}^{-1}, 2.83 \mathrm{mmol} \mathrm{g}^{-1}, 1.94 \mathrm{mmol} \mathrm{g}^{-1}, 1.76 \mathrm{mmol} \mathrm{g}^{-1}$, and $1.01 \mathrm{mmol} \mathrm{g}^{-1}$, respectively. The comparison with other reagents is shown in Table 3 and shows that the amount of $\mathrm{Cr}(\mathrm{VI}), \mathrm{Pb}$ (II), $\mathrm{Cr}$ (III), $\mathrm{Zn}$ (II), and $\mathrm{Cd}(\mathrm{II})$ adsorbed by the P4VP-g-PS resin is far higher than those of the other adsorbents. ATRP reaction increases the density of the pyridine ring on the surface of P4VP-g-PS resin, such that the resin has a relatively high adsorptive capacity. This indicates that the adoption of ATRP technology to graft the functional monomer on the resin surface is an effective method to prepare a high-capacity chelating resin.

3.3.2 Effects of the experimental conditions on the adsorption performance of the product

(1) Effect of medium $\mathrm{pH}$. Solution $\mathrm{pH}$ has a direct effect on the adsorption sites, adsorbent surface, and chemical morphology of the metal ions. As for most adsorption processes, $\mathrm{pH}$ value not only affects the characteristics of the composition of the surface structures of polymeric adsorbents but also affects the chemical identity of the heavy metal ions in the solution, thereby shifting the adsorption equilibrium.

Fig. 9 presents a plot of the amount of adsorbed metal ions at equilibrium state versus $\mathrm{pH}$, indicating that changes in the $\mathrm{pH}$ value have great effects on the amount of $\mathrm{Cr}(\mathrm{VI}), \mathrm{Pb}$ (II), $\mathrm{Cr}$ (III), $\mathrm{Zn}$ (II), and $\mathrm{Cd}(\mathrm{II})$ adsorbed by the resin. In the case of a $\mathrm{pH}$ value of 3.0, the adsorptive capacity for $\mathrm{Cr}(\mathrm{vI})$ was the strongest, whereas in the case of a $\mathrm{pH}$ value of 5.0, the adsorption capacity for $\mathrm{Pb}$ (II), $\mathrm{Cr}$ (III), $\mathrm{Zn}$ (II), and $\mathrm{Cd}(\mathrm{II})$ reached a peak value. The reason behind this phenomenon is the formation of ions and chelating functionality at different $\mathrm{pH}$ environments:

(1) When the $\mathrm{pH}$ value was relatively low, the $\mathrm{N}$ atom on the pyridine ring is easy to be protonated and loaded with positive charges; thus, the adsorptive capacity for $\mathrm{Pb}$ (II), $\mathrm{Cr}$ (III), $\mathrm{Zn}$ (II), and $\mathrm{Cd}(\mathrm{II})$ is relatively poor. A very high concentration of $\mathrm{H}^{+}$at the interface had electrostatic repulsion effects on the positively charged $\mathrm{Pb}$ (II), $\mathrm{Cr}$ (III), $\mathrm{Zn}$ (II), and $\mathrm{Cd}$ (II) ions, thereby preventing their approach to the resin surface. A low $\mathrm{pH}$ value meant

Table 2 Langmuir and Freundlich constants for $\mathrm{Cr}(\mathrm{VI}), \mathrm{Pb}(\Perp), \mathrm{Cr}(\mathrm{II}), \mathrm{Zn}(॥)$, and $\mathrm{Cd}(॥)$ adsorption on PVT resins at $25^{\circ} \mathrm{C}$

Langmuir parameters

Metal ions

$\operatorname{Cd}($ II)

$\mathrm{Zn}(\mathrm{II})$

$\operatorname{Cr}($ III)

$\mathrm{Pb}(\mathrm{II})$

$\mathrm{Cr}(\mathrm{vI})$

$Q_{0}\left(\mathrm{mmol} \mathrm{g}^{-1}\right)$

\subsection{6}

2.108

2.086

3.11

4.695

b

$K_{\mathrm{C}}$

60

65.67

99.94

102.28

72.33
Freundlich parameters

\begin{tabular}{lll} 
& $\frac{1}{n}$ & $R_{\mathrm{F}}{ }^{2}$ \\
\hline 1.114 & 0.6262 & 0.97244 \\
0.649 & 0.6192 & 0.9702 \\
1.797 & 0.7999 & 0.94258 \\
0.719 & 0.6393 & 0.9569 \\
2.322 & 0.7601 & 0.97896
\end{tabular}


Table 3 Comparison of $\mathrm{Cr}(\mathrm{VI}), \mathrm{Pb}(॥), \mathrm{Cr}(\| I), \mathrm{Zn}(\|)$, and $\mathrm{Cd}(॥)$ adsorption on the P4VP-g-PS resins with other adsorbents

\begin{tabular}{|c|c|c|c|c|c|c|}
\hline \multirow[b]{2}{*}{ Adsorbents } & \multicolumn{5}{|c|}{ Adsorption capacities $\left(\mathrm{mmol} \mathrm{g}^{-1}\right)$} & \multirow[b]{2}{*}{ Reference } \\
\hline & $\mathrm{Cr}(\mathrm{vI})$ & $\mathrm{Pb}(\mathrm{II})$ & $\mathrm{Cr}(\mathrm{III})$ & $\mathrm{Zn}(\mathrm{II})$ & $\mathrm{Cd}(\mathrm{II})$ & \\
\hline $\begin{array}{l}\text { 4-Vinyl pyridine/2- } \\
\text { hydroxyethylmethacrylate, monomer } \\
\text { mixture grafted poly(ethylene } \\
\text { terephthalate) fiber }\end{array}$ & 1.56 & - & - & - & 0.20 & 21 \\
\hline $\begin{array}{l}\text { Amino-functionalized magnetic cellulose } \\
\text { nanocomposite }\end{array}$ & 3.28 & - & & - & - & 22 \\
\hline GA-APTES-glass beads & 0.223 & 0.048 & - & - & - & 23 \\
\hline $\begin{array}{l}\text { Novel } \mathrm{Fe}_{3} \mathrm{O}_{4} \text { magnetic nanoparticles } \\
\text { (MNPs) modified with 3- } \\
\text { aminopropyltriethoxysilane, (APS) and } \\
\text { copolymers of acrylic acid (AA) and } \\
\text { crotonic acid (CA) }\end{array}$ & - & 0.37 & - & 0.61 & 0.29 & 24 \\
\hline $\begin{array}{l}\text { poly(glycidyl methacrylate-co-ethylene } \\
\text { dimethacrylate) monolith functionalized } \\
\text { with ethylenediamine }\end{array}$ & - & 0.537 & 3.633 & - & - & 25 \\
\hline Sugar beet pulp & - & 0.35 & - & 0.27 & 0.42 & 26 \\
\hline Salicylic acid type chelate adsorbent & - & 0.42 & - & 0.48 & 0.98 & 27 \\
\hline P4VP-g-PS resins & 4.56 & 2.83 & 1.94 & 1.76 & 1.01 & This work \\
\hline
\end{tabular}

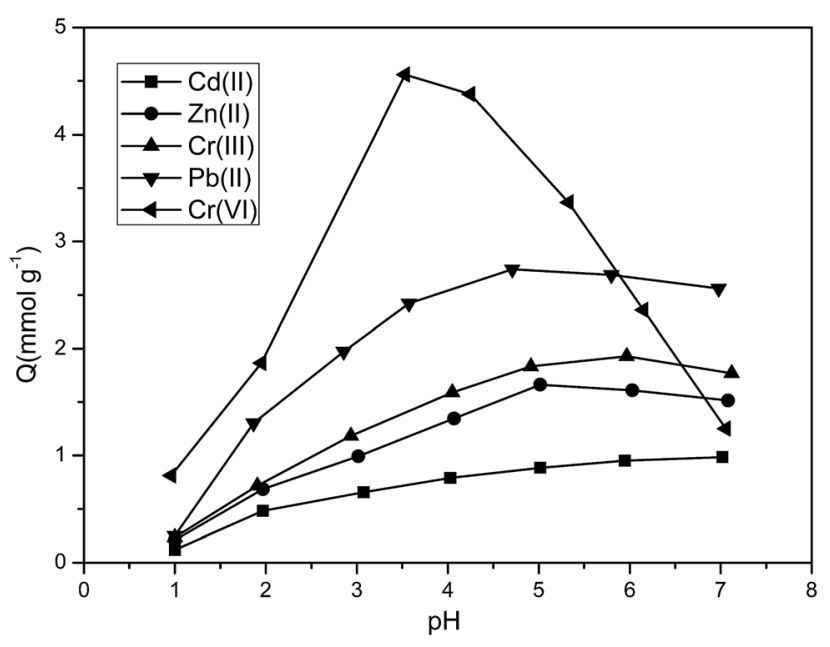

Fig. 9 Effect of $\mathrm{pH}$ on the adsorption of P4VP-g-PS resin for $\mathrm{Cr}(\mathrm{VI})$, $\mathrm{Pb}(॥), \mathrm{Cr}\left({ }^{\prime \prime}\right), \mathrm{Zn}(॥)$, and $\mathrm{Cd}(॥)$ (initial concentration: $6 \mathrm{mmol} \mathrm{L}^{-1} ; 25^{\circ} \mathrm{C}$; adsorbent dose: $0.1 \mathrm{~g}$ ).

a more obvious protonation effect; a smaller number of nitrogen atoms that experience chelation will be unfavorable to the reaction with the metal ions and will decrease the adsorption performance. In the case of a $\mathrm{pH}$ value of 5.0, the $\mathrm{N}$ atom on the pyridine ring is electroneutral, but it contains a lone electron pair, which can adsorb $\mathrm{Pb}$ (II), Cr(III), Zn(II), and $\mathrm{Cd}$ (II) ions, as shown in Fig. 10.

(2) The stability curve of $\mathrm{Cr}(\mathrm{vI})^{28,29}$ showed that the main form of $\mathrm{Cr}(\mathrm{vI})$ in the solution is $\mathrm{HCrO}_{4}{ }^{-}, \mathrm{CrO}_{4}{ }^{2-}, \mathrm{Cr}_{2} \mathrm{O}_{7}{ }^{2-}$, and other oxygen-containing anions. In the case of a relatively low $\mathrm{pH}$ value, $\mathrm{HCrO}_{4}{ }^{-}$is the main species, whereas $\mathrm{CrO}_{4}{ }^{2-}$ is the main form at a $\mathrm{pH}$ greater than 7.0. In the case of a $\mathrm{pH}$ value of 3.0, the $\mathrm{N}$ atom on the pyridine is protonated and positively charged, and the protonated groups can attract the anions

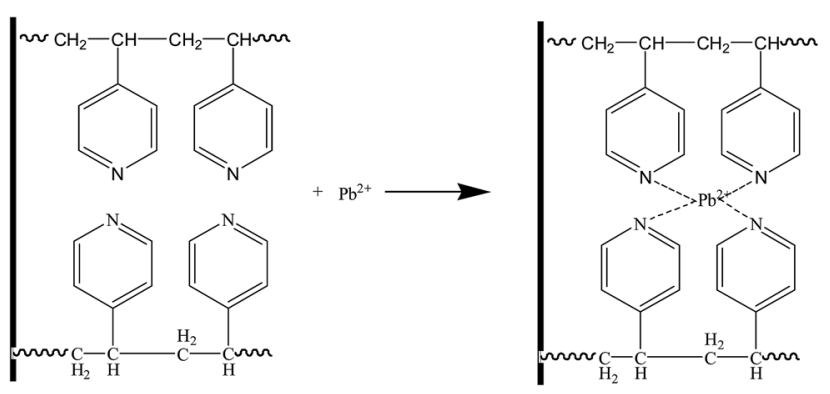

Fig. 10 Adsorption mechanism of P4VP-g-PS resins for $\mathrm{Pb}(॥)$.

including $\mathrm{Cr}(\mathrm{vI})$ through the electrostatic interactions. In the case of an increase in the $\mathrm{pH}$ value, the protonated groups relatively decrease and the adsorption of $\mathrm{Cr}(\mathrm{vI})$ through electrostatic interactions is not important anymore, as shown in Fig. 11.

The abovementioned analysis indicate that the optimum $\mathrm{pH}$ value for the selective separation of $\mathrm{Cr}(\mathrm{VI})$ from $\mathrm{Pb}(\mathrm{II}), \mathrm{Cr}(\mathrm{III})$, $\mathrm{Zn}$ (II), and Cd(II) was 3.0.

(2) Effects of temperature. Temperature is an important parameter that affects the adsorption process, and Fig. 12 presents the adsorption isotherms of P4VP- $g$-PS resin for $\mathrm{Cr}(\mathrm{VI})$,

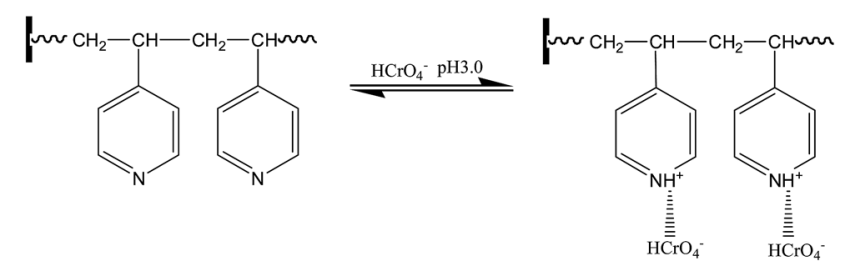

Fig. 11 Adsorption mechanism of P4VP-g-PS resins for $\mathrm{Cr}(\mathrm{VI})$. 

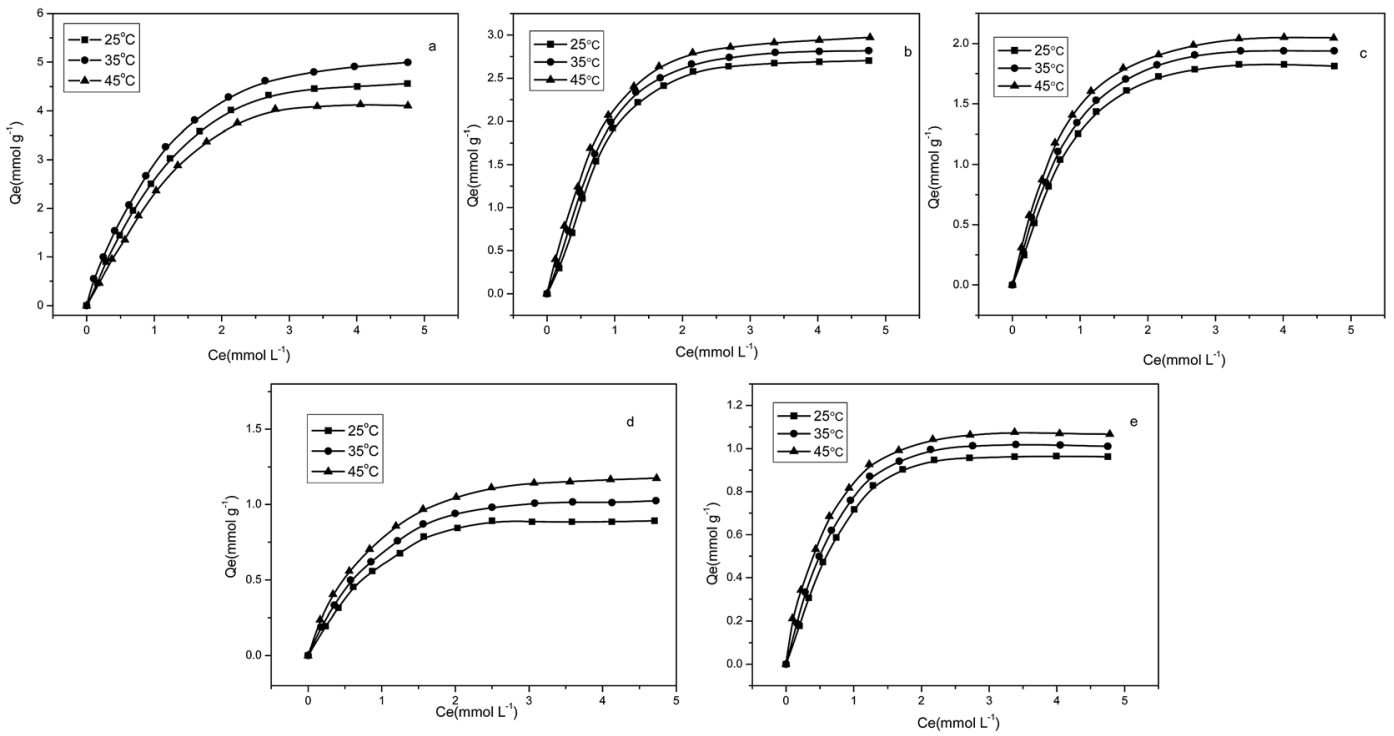

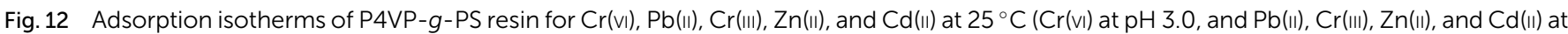
$\mathrm{pH}$ 5.0; contact time: $12 \mathrm{~h}$; adsorbent dose: $0.1 \mathrm{~g}$ ).

$\mathrm{Pb}$ (II), $\mathrm{Cr}$ (III), $\mathrm{Zn}$ (II), and $\mathrm{Cd}(\mathrm{II})$ at different temperatures. As shown in the images, with the increase in temperature, the adsorptive capacity of the P4VP-g-PS resin for various kinds of metal ions slightly increases. With the increase in temperature, the ions are more apt to diffuse and the resin will become dilated to varying degrees, leading to a certain increase in the adsorptive capacity. However, the effects of temperature on the adsorptive capacity were not significant.

A thermodynamic study was employed to better explain the reaction process, and some thermodynamic studies, such as Gibbs free energy $(\Delta G)$, enthalpy change $(\Delta H)$, and entropy change $(\Delta S)$, can be obtained through the calculation via the following formulas (7) and (8):

$$
\begin{aligned}
& \Delta G=-R T \ln K_{\mathrm{C}} \\
& \Delta G=\Delta H-T \Delta S
\end{aligned}
$$

where $R$ represents the gas constant $8.314 \mathrm{~J} \mathrm{~K}^{-1} \mathrm{~mol}^{-1}, T$ is the absolute temperature $(\mathrm{K})$, and $K_{\mathrm{C}}$ is the adsorption equilibrium constant, which can be obtained from the Langmuir adsorption isotherm at different temperatures.

The van't Hoff equation can be deduced through the formulas (7) and (8) as follows:

$$
\ln K_{\mathrm{C}}=-\Delta H / R T+\Delta S / R
$$

The results of the analysis of data presented in Fig. 12 using formulas (7) to (9) are shown in Table 4.

As shown in the analysis of the thermodynamic data in Table $4, \Delta G$ is a negative value, indicating that the adsorption process of P4VP-g-PS resin on the metal ions is spontaneous; with the increase in temperature, $\Delta G$ value slightly decreases, indicating that the adsorptive capacity will somewhat increase at a relatively high temperature. $\Delta H$ and $\Delta S$ were positive, indicating
Table 4 Thermodynamic parameters estimated for the adsorption of five metal ions on the P4VP-g-PS resins

\begin{tabular}{lllllll}
\hline & & & \multicolumn{4}{c}{$\Delta G\left(\mathrm{~kJ} \mathrm{~mol}^{-1}\right)$} \\
\cline { 5 - 6 } Metal ions & $\begin{array}{l}\Delta H \\
\left(\mathrm{~kJ} \mathrm{~mol}^{-1}\right)\end{array}$ & $\begin{array}{l}\Delta S \\
\left(\mathrm{~J} \mathrm{~mol}^{-1} \mathrm{~K}^{-1}\right)\end{array}$ & $25{ }^{\circ} \mathrm{C}$ & $35{ }^{\circ} \mathrm{C}$ & $45{ }^{\circ} \mathrm{C}$ \\
\hline $\mathrm{Cd}(\mathrm{II})$ & 5.594 & 52.8 & -10.14 & -10.65 & -11.23 \\
$\mathrm{Zn}(\mathrm{II})$ & 2.384 & 42.8 & -10.37 & -10.79 & -11.24 \\
$\mathrm{Cr}(\mathrm{III})$ & 5.576 & 57 & -11.41 & -11.98 & -12.55 \\
$\mathrm{~Pb}(\mathrm{II})$ & 10.433 & 73.5 & -11.47 & -12.19 & -12.97 \\
$\mathrm{Cr}(\mathrm{VI})$ & 7.508 & 60.8 & -10.61 & -11.21 & -11.84 \\
& & & & &
\end{tabular}

that the adsorption process of P4VP- $g$-PS resin on metal ions was a heat-absorbing and entropy-driven spontaneous process.

3.3.3 Adsorption dynamics. Adsorption dynamics describe the rate of adsorption of metal ions by resin, which is one of the most important factors for the investigation of resin adsorption performance. The adsorption kinetic curve of P4VP-g-PS against $\mathrm{Cr}(\mathrm{VI}), \mathrm{Pb}(\mathrm{II}), \mathrm{Cr}(\mathrm{III}), \mathrm{Zn}(\mathrm{II})$, and $\mathrm{Cd}(\mathrm{II})$ are shown in Fig. 13.

As shown in Fig. 13, the adsorption rate was relatively rapid at the beginning, and then it gradually flattened out. The time taken by the five kinds of metal ions to reach the adsorption equilibrium is within $120 \mathrm{~min}$. During metal ion adsorption by porous adsorbents, metal ions must first reach the boundary, then diffuse to the resin surface and enter the porous structures of the resin to bind with the chelation sites. Therefore, a relatively long contact time is required during the adsorption process.

The adsorption mechanism of resin can be predicted through the adsorption kinetic study. The ion exchange process was very rapid and mainly controlled through the diffusion rate. Chelation was activated very slowly and was often dependent on the particle diffusion mechanism of a quasi-secondary reaction.

The kinetic equation of a quasi-secondary reaction is given as follows: 


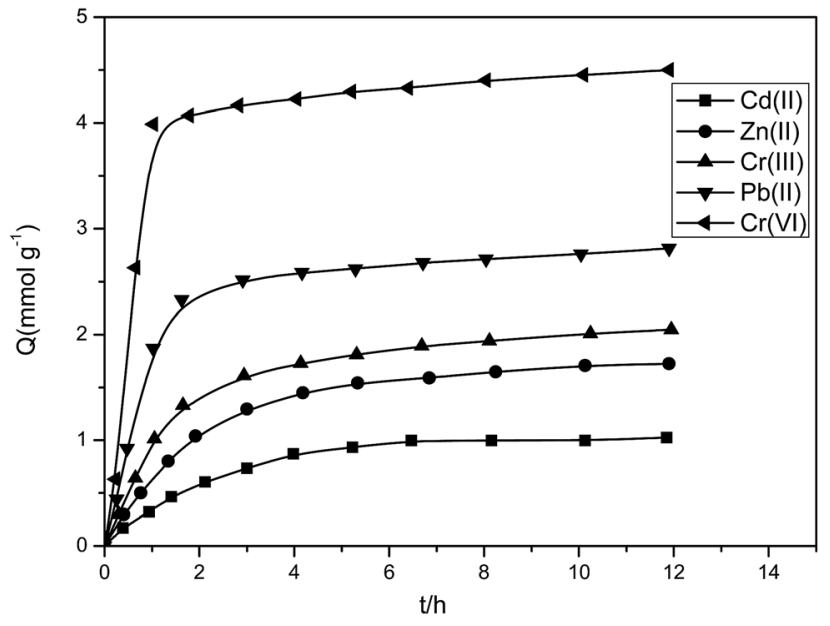

Fig. 13 Adsorption kinetics of P4VP-g-PS resin for $\mathrm{Cr}(\mathrm{VI}), \mathrm{Pb}(\mathrm{II}), \mathrm{Cr}(\mathrm{II})$, $\mathrm{Zn}(॥)$, and $\mathrm{Cd}(॥)$ (initial concentration: $5 \mathrm{mmol} \mathrm{L}^{-1} ; \mathrm{Cr}(\mathrm{VI})$ at $\mathrm{pH} 3.0, \mathrm{~Pb}(॥)$, $\mathrm{Cr}(\mathrm{III}), \mathrm{Zn}(\mathrm{II})$, and $\mathrm{Cd}(\mathrm{II}) \mathrm{pH}$ 5.0; $25^{\circ} \mathrm{C}$; adsorbent dose: $0.1 \mathrm{~g}$ ).

$$
\frac{t}{Q_{t}}=\frac{1}{k Q_{\mathrm{e}}{ }^{2}}+\frac{1}{Q_{\mathrm{e}}} t
$$

where $t$ represents the adsorption time (h), $k$ is the adsorption rate constant $\left(\mathrm{g} \mathrm{mmol}^{-1} \mathrm{~h}^{-1}\right.$ ), and $Q_{t}$ and $Q_{\mathrm{e}}$ represent the time $t$ and the adsorptive capacity when the equilibrium is achieved $\left(\mathrm{mmol} \mathrm{g}^{-1}\right)$.

Formula (10) is used for the curve fitting of the adsorption kinetic data; plotting of $t / Q_{t}$ against $t$ generated a straight line. The linearly dependent coefficient of the straight line was greater than 0.998, indicating that adsorption of resin for $\mathrm{Cr}(\mathrm{vI})$, $\mathrm{Pb}(\mathrm{II}), \mathrm{Cr}(\mathrm{III}), \mathrm{Zn}$ (II), and $\mathrm{Cd}(\mathrm{II})$ conformed to a quasi-secondary kinetic model and further proved that the P4VP- $g$-PS resin adsorbed the metal ions via chelation effects. Through the intercept and the slope of the straight line, the reaction rate constant of $\mathrm{Cr}(\mathrm{VI}), \mathrm{Pb}$ (II), $\mathrm{Cr}$ (III), $\mathrm{Zn}$ (II), and $\mathrm{Cd}(\mathrm{II})$ were obtained to be $0.689,0.703,0.375,0.230$, and $0.194 \mathrm{~g} \mathrm{mmol}^{-1} \mathrm{~h}^{-1}$.

3.3.4 Selective adsorption. P4VP- $g$-PS resin can selectively separate $\mathrm{Cr}(\mathrm{vI})$ from the secondary or quinary solution. In the case of a $\mathrm{pH}$ value of 3.0, P4VP- $g$-PS adsorbs metal ions from the solutions containing the same concentration of $\mathrm{Cr}(\mathrm{VI}), \mathrm{Pb}(\mathrm{II})$, Cr(III), Zn(II) and Cd(II), and the results are shown in Fig. 14.

Under normal circumstances, electrostatic interactions, surface complexation, and ion exchange are often considered as the main adsorption mechanisms. As previously reported, the pyridine ring functional groups on the resin surface can effectively adsorb $\mathrm{Cr}(\mathrm{vI})^{30}$ in a solution. Therefore, the interaction between the P4VP-g-PS resin and metal ions mainly depends on the pyridine rings on the resin surface. In a multicomponent system, P4VP-g-PS presents a relatively high affinity for $\mathrm{Cr}(\mathrm{vI})$ and the existence of $\mathrm{Zn}$ (II) and $\mathrm{Cd}$ (II) in the solution has few effects on the adsorption of $\mathrm{Cr}(\mathrm{vI})$ by P4VP- $g$-PS resin. In the binary solutions of $\mathrm{Cr}(\mathrm{VI})-\mathrm{Zn}(\mathrm{II}), \mathrm{Cr}(\mathrm{VI})-\mathrm{Cd}(\mathrm{II}), \mathrm{Cr}(\mathrm{VI})-\mathrm{Cr}(\mathrm{III})$, and $\mathrm{Cr}(\mathrm{VI})-\mathrm{Pb}$ (II) and the quinary $\mathrm{Cr}$ (VI) $-\mathrm{Pb}$ (II) $-\mathrm{Cr}$ (III) $-\mathrm{Zn}$ (II)-Cd(II) systems, the adsorption selectivity for $\mathrm{Cr}(\mathrm{vI})$ was as high as $98 \%$. In the case of a $\mathrm{pH}$ value of 3.0, P4VP-g-PS resin highly selectively adsorbs $\mathrm{Cr}(\mathrm{vI})$ in the secondary or quinary solution. Therefore, in the solution containing $\mathrm{Pb}(\mathrm{II}), \mathrm{Cr}$ (VI), $\mathrm{Cr}$ (III), $\mathrm{Zn}$ (II), and C(II), P4VP-g-PS resin quantitatively and selectively adsorbed $\mathrm{Cr}(\mathrm{vI})$ via controlling the $\mathrm{pH}$ value of solution.

3.3.5 Resin desorption and performance for repeated use. Fig. 15 displays the process of using $1 \mathrm{~mol} \mathrm{~L}^{-1} \mathrm{KOH}$ solution for the desorption of $\mathrm{Cr}(\mathrm{vI})$ and $0.1 \mathrm{~mol} \mathrm{~L}^{-1} \mathrm{HNO}$ solution for the desorption of $\mathrm{Pb}(\mathrm{II}), \mathrm{Cr}(\mathrm{III}), \mathrm{Zn}$ (II), and $\mathrm{Cd}(\mathrm{II})$, indicating that the metal ions can be easily desorbed within $60 \mathrm{~min}$. The studies on the metal ion desorption further proved that there is electrostatic interaction between $\mathrm{Cr}(\mathrm{VI})$ and P4VP- $g$-PS resin.

To investigate the regeneration performance of the resin, the metal ions were adsorbed and desorbed using the same method over ten cycles, and the experimental results are shown in Table 5.
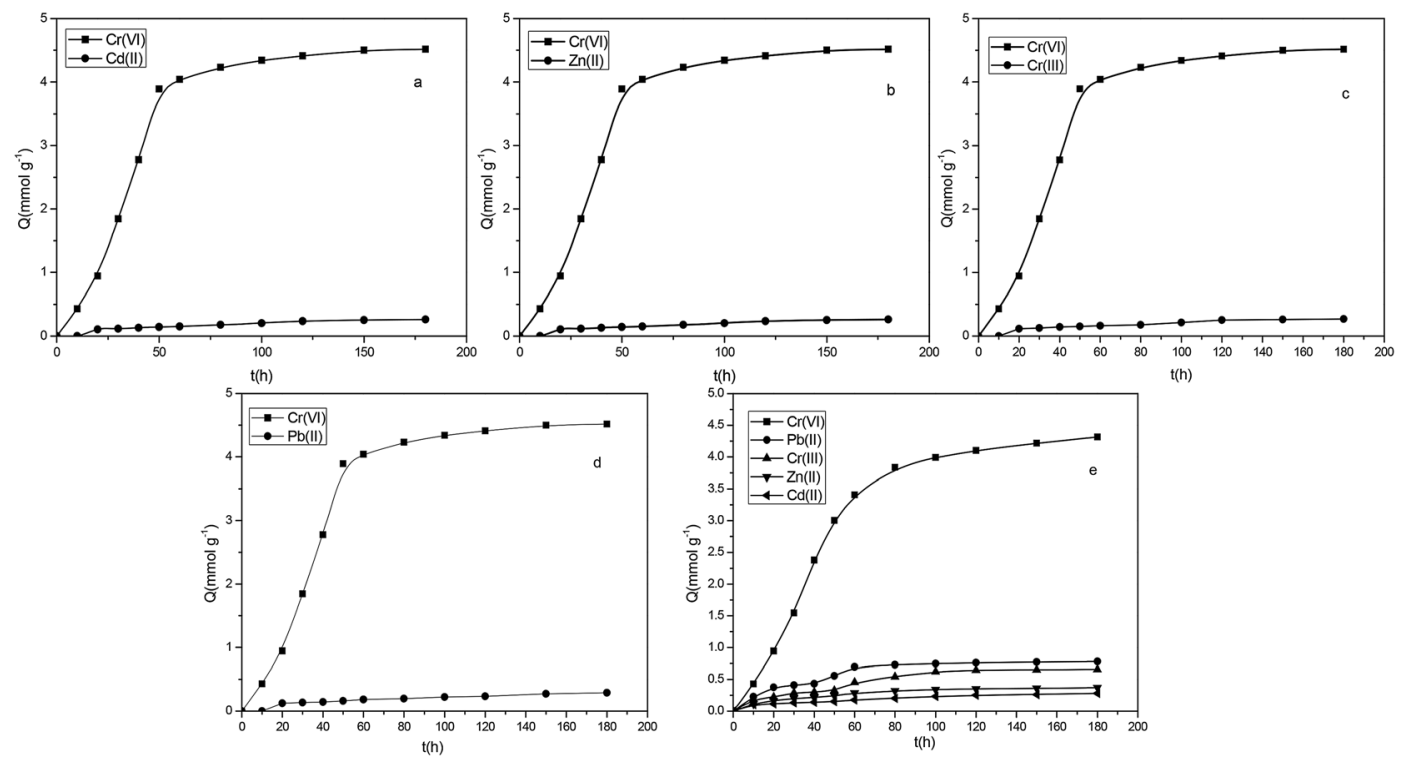

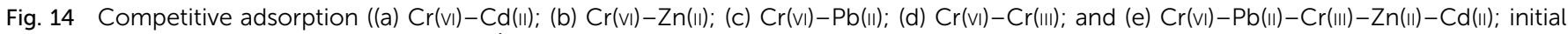
concentration of each metal ion: $5 \mathrm{mmol} \mathrm{L}^{-1}$; $\mathrm{pH} 3.0$; temperature $25^{\circ} \mathrm{C}$ ). 


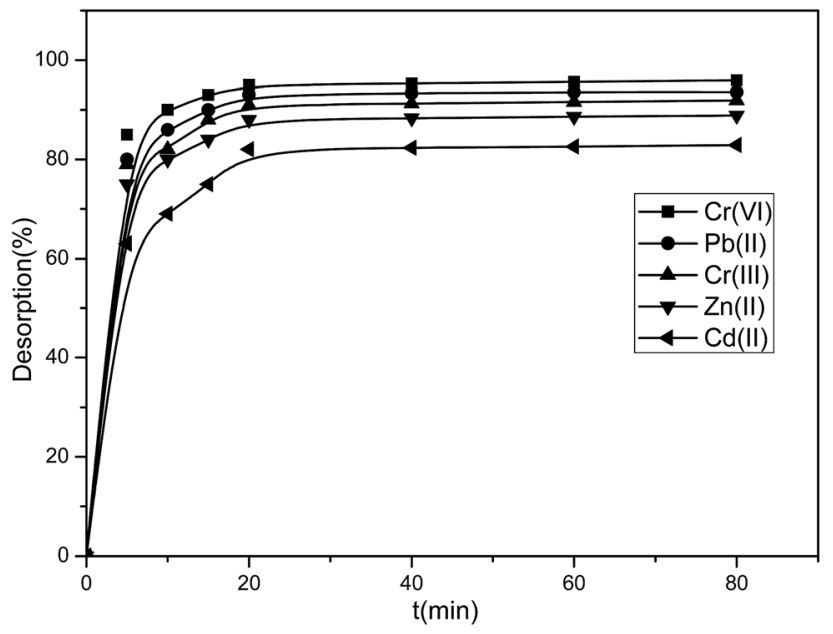

Fig. 15 The desorption curve of P4VP-g-PS resins.

Table 5 Adsorption and desorption behaviors of $\mathrm{Cr}(\mathrm{VI}), \mathrm{Pb}(\mathrm{II}), \mathrm{Cr}(\mathrm{III})$, $\mathrm{Zn}(\|)$, and $\mathrm{Cd}(\|)$ adsorption on the P4VP-g-PS resins

\begin{tabular}{llllll}
\hline \multirow{5}{*}{ Cycle } & \multicolumn{5}{l}{ Adsorption capacities $\left(\mathrm{mmol} \mathrm{g}^{-1}\right)$} \\
\cline { 2 - 6 } & $\mathrm{Cd}(\mathrm{II})$ & $\mathrm{Zn}(\mathrm{II})$ & $\mathrm{Cr}(\mathrm{III})$ & $\mathrm{Pb}(\mathrm{II})$ & $\mathrm{Cr}(\mathrm{VI})$ \\
\hline 1 & 1.01 & 1.76 & 1.94 & 2.83 & 4.56 \\
2 & 1.00 & 1.76 & 1.93 & 2.82 & 4.56 \\
3 & 1.00 & 1.74 & 1.93 & 2.82 & 4.56 \\
4 & 0.97 & 1.75 & 1.92 & 2.81 & 4.54 \\
5 & 0.98 & 1.74 & 1.92 & 2.80 & 4.53 \\
6 & 0.95 & 1.73 & 1.90 & 2.83 & 4.55 \\
7 & 0.97 & 1.75 & 1.91 & 2.82 & 4.52 \\
8 & 0.96 & 1.74 & 1.92 & 2.79 & 4.53 \\
9 & 0.99 & 1.73 & 1.91 & 2.78 & 4.54 \\
10 & 0.95 & 1.72 & 1.91 & 2.79 & 4.52 \\
\hline
\end{tabular}

As shown in Table 5, after 10 adsorption-desorption cycles, the adsorptive capacity for $\mathrm{Cr}(\mathrm{VI})$ decreased by only $0.88 \%$, whereas that for $\mathrm{Pb}$ (II), $\mathrm{Cr}$ (III), $\mathrm{Zn}$ (II), and $\mathrm{Cd}$ (II) decreased by $1.41 \%, 1.55 \%, 2.27 \%$, and $5.94 \%$, respectively. This fully demonstrated that P4VP-g-PS resin has excellent performance for repeated use.

\section{Conclusion}

The utilization of SI-ATRP technology in a one-step method to directly graft 4 -vinylpyridine on the CMPS resin can make it feasible to prepare the 4-vinylpyridine-modified chelating resin. Prolonged polymerization time and increased monomer dosage resulted in linear increases in the degree of grafting and corresponding increases in the adsorptive capacity for the heavy metal ions. This indicated that the number of pyridine rings on the resin surface also increased. The control of ATRP time and monomer dosage effectively controlled the density of the functional groups on the resin surface as well as the polymer grafting amount and avoided the disadvantages of the resin hole obstruction resulting from other methods that cannot control the surface modification.
The maximal adsorptive capacities of 4-vinylpyridine resin for $\mathrm{Cr}(\mathrm{VI}), \mathrm{Pb}(\mathrm{II}), \mathrm{Cr}(\mathrm{III}), \mathrm{Zn}$ (II), and $\mathrm{Cd}(\mathrm{II})$ were $4.56 \mathrm{mmol} \mathrm{g}^{-1}$, $2.83 \mathrm{mmol} \mathrm{g}^{-1}, 1.94 \mathrm{mmol} \mathrm{g}^{-1}, 1.76 \mathrm{mmol} \mathrm{g}^{-1}$, and $1.01 \mathrm{mmol}$ $\mathrm{g}^{-1}$, respectively. When the $\mathrm{pH}$ value was greater than 5.0, the resin can adsorb $\mathrm{Pb}$ (II), $\mathrm{Cr}$ (III), $\mathrm{Zn}$ (II), and $\mathrm{Cd}$ (II) ions; when the $\mathrm{pH}$ value was less than 3.0 , the resin can selectively adsorb $\mathrm{Cr}(\mathrm{vI})$. The method has a good metal ion desorption rate and good performance for repeated use, without obvious change in the adsorptive capacity. Therefore, 4-vinylpyridine resin had potential prospects of application during the processing of heavy metal wastewater.

\section{Acknowledgements}

This work was supported by the Special Research Projects of Education Department of Shaanxi provincial Government (no. 15JK1782), the Key Project of Specialized Research Foundation, Xianyang Normal College (no. 15XYYK037), and the Natural Science Foundation of Shaanxi Province, China (no. 2013JM2016).

\section{References}

$1 \mathrm{E}$. Guibal, Interactions of metal ions with chitosan-based sorbents: a review, Sep. Purif. Technol., 2004, 38, 43-74.

2 P. Liu, W. M. Liu and Q. J. Xue, Preparation of comb-like polystyrene grafted silica nanoparticles, J. Macromol. Sci., Part A: Pure Appl.Chem., 2004, 41, 1001-1010.

3 Q. Yuan, N. Li, Y. Chi, et al., Effect of large pore size of multifunctional mesoporous microsphere on removal of heavy metal ions, J. Hazard. Mater., 2013, 254-255, 157-165.

$4 \mathrm{~N}$. M. Wu and Z. K. Li, Synthesis and characterization of poly(HEA/MALA) hydrogel and its application in removal of heavy metal ions from water, Chem. Eng. J., 2013, 215-216, 894-902.

5 J. B. Dong, J. B. Wu, J. Yang, et al., Preparation of Highcapacity IDA Chelating Resin and Its Adsorption Properties, Chem. J. Chin. Univ., 2013, 34(3), 714-719.

6 J. C. Zhang and Y. N. Chen, Uptake of Fe(III), Ag(I), Ni(II) and $\mathrm{Cu}(\mathrm{II})$ by salicylic acid-type chelating resin prepared via surface initiated atom transfer radical polymerization, $R S C$ Adv., 2016, 6, 69370-69380.

7 C. Shen, Y. Chang, L. Fang, M. Min and C. H. Xiong, Selective removal of copper with polystyrene-1,3-diaminourea chelating resin: synthesis and adsorption studies, New J. Chem., 2016, 40, 3588-3596.

8 X. J. Dai, Y. He, Y. M. Wei, et al., Preparation of hydrophilic polymer-grafted polystyrene beads for hydrophilic interaction chromatography via surface-initiated atom transfer radical polymerization, J. Sep. Sci., 2013, 34(22), 3115-3122.

9 C. H. Xiong, Y. L. Li and G. T. Wang, Selective removal of $\mathrm{Hg}$ (II) with polyacrylonitrile-2-amino-1,3,4-thiadiazole chelating resin: batch and column study, Chem. Eng. J., 2015, 259, 257-265.

10 M. X. Liu, Y. Sun, S. B. Na, et al., Selective adsorption of lead(II) from aqueous solution by ion-imprinted PEI- 
functionalized silica sorbent: studies on equilibrium isotherm, kinetics, and thermodynamics, Desalin. Water Treat., 2016, 57, 3270-3282.

11 Y. M. Wei, J. J. Ma and C. Z. Wang, Preparation of highcapacity strong cation exchange membrane for protein adsorption via surface-initiated atom transfer radical polymerization, J. Membr. Sci., 2013, 427, 197-206.

12 X. L. Qian, H. Fan, C. Z. Wang, et al., Preparation of highcapacity, weak anion-exchange membranes by surfaceinitiated atom transfer radical polymerization of poly(glycidylmethacrylate) and subsequent derivatization with diethylamine, Appl. Surf. Sci., 2013, 271, 240-247.

13 P. B. Dutra, A. T. Toci, C. A. S. Riehl, et al., Adsorption of some elements from hydrochloric acid by anion exchange, Eur. Polym. J., 2005, 41(8), 1943-1946.

14 N. Fontanals, R. M. Marce, M. Galia, et al., Preparation and characterization of highly polar polymeric sorbents from styrene-divinylbenzene and vinylpyridine-divinylbenzene for the solid-phase extraction of polar organic pollutants, $J$. Polym. Sci., Part A: Polym. Chem., 2003, 41(13), 1927-1933.

15 L. C. S. Maria, A. P. Aguiar, M. R. M. P. Aguiar, et al., Microscopic analysis of porosity of 2-vinylpyridine copolymer networks: 1 . Influence of diluent, Mater. Lett., 2004, 58(5), 563-568.

16 K. Matyjaszewski, T. E. Patten and J. Xia, Controlled/“Living” Radical Polymerization. Kinetics of the Homogeneous Atom Transfer Radical Polymerization of Styrene, J. Am. Chem. Soc., 1997, 119(4), 674-680.

17 C. F. Huang, S. W. Kuo, J. K. Chen, et al., Synthesis and Characterization of Polystyrene- $b$-Poly(4-vinyl pyridine) Block Copolymers by Atom Transfer Radical Polymerization, J. Polym. Res., 2005, 12(6), 449-456.

18 M. A. Mohammad, A. A. Zeid, N. Mu, et al., Evaluation of heavy metal kinetics through pyridine based Th(Iv) phosphate composite cation exchanger using particle diffusion controlled ion exchange phenomenon, J. Ind. Eng. Chem., 2014, 20, 705-709.

19 K. Inderjeet, K. Vandna, S. Bharti, et al., Characterization and applications of PVF film grafted with binary mixture of methacrylic acid and 4-vinyl pyridine by gamma radiations: effect of swift heavy ions, Appl. Radiat. Isot., 2013, 79, 118-130.
20 A. Duran, M. Soylak and S. A. Tuncel, Poly(vinyl pyridine-poly ethylene glycol methacrylate-ethylene glycol dimethacrylate) beads for heavy metal removal, J. Hazard. Mater., 2008, 155, 114-120.

21 Y. Mustafa and A. Metin, Selective removal of $\mathrm{Cr}(\mathrm{VI})$ ions from aqueous solutions including $\mathrm{Cr}(\mathrm{VI}), \mathrm{Cu}(\mathrm{II})$ and $\mathrm{Cd}(\mathrm{II})$ ions by 4-vinyl pyridine/2-hydroxyethylmethacrylate monomer mixture grafted poly(ethylene terephthalate) fiber, J. Hazard. Mater., 2009, 166, 435-444.

22 X. T. Sun, R. L. Yang, Q. Li, et al., Amino-functionalized magnetic cellulose nanocomposite as adsorbent for removal of $\mathrm{Cr}(\mathrm{vI})$ : synthesis and adsorption studies, Chem. Eng. J., 2014, 241, 175-183.

23 O. Mustafa, C. Keziban, A. Ilker, et al., Surface modification of glass beads with glutaraldehyde: characterization and their adsorption property for metal ions, J. Hazard. Mater., 2009, 171, 594-600.

24 F. Ge, M. M. Li, H. Ye, et al., Effective removal of heavy metal ions $\mathrm{Cd}^{2+}, \mathrm{Zn}^{2+}, \mathrm{Pb}^{2+}, \mathrm{Cu}^{2+}$ from aqueous solution by polymer-modified magnetic nanoparticles, J. Hazard. Mater., 2012, 211-212, 366-372.

25 H. X. Wang, H. Y. Zhang, Y. Q. Lv, et al., Polymer monoliths with chelating functionalities for solid phase extraction of metal ions from water, J. Chromatogr. A, 2014, 1343, 128-134.

26 Z. Reddad, C. Gerente and Y. Andres, Adsorption of several metal ions onto a low-cost biosorbent: kinetic and equilibrium studies, Environ. Sci. Technol., 2002, 36, 20672073.

27 F. An, B. Gao and X. Dai, Efficient removal of heavy metal ions from aqueous solution using salicylic acid type chelate adsorbent, J. Hazard. Mater., 2011, 192, 956-962.

28 J. Paradhan, S. N. Das and R. S. Thakur, Adsorption of hexavalent chromium from aqueous solution by using activated red mud, J. Colloid Interface Sci., 1999, 217, 137141.

29 L. D. Benefield, J. F. Judkins and B. L. Weand, Process Chemistry for Water and Wastewater Treatment, PrenticeHall, Englewood Cliffs, 1982.

30 R. S. Bai and T. E. Abraham, Studies on enhancement of $\mathrm{Cr}(\mathrm{vI})$. Biosorption by chemically modified biomass of Rhizopus nigricans, Water Res., 2002, 36(5), 1224-1236. 